\title{
RESEARCH ON OPTIMIZATION MODEL OF MARINE INDUSTRY STRATEGIC ADJUSTMENT UNDER COMPLEX MARITIME CONDITIONS BASED ON ANT COLONY ALGORITHM
}

\author{
Xiao Shen, Ph. D. \\ School of Business, Xinyang Normal University, Xinyang, Henan, China
}

\begin{abstract}
This article seeks to analyze the factors constraining the development of strategic marine emerging industries and the deficiencies in China's strategic marine emerging industry development policies. Learn from the successful experiences of overseas strategic marine emerging industry development policies. We will study and construct a policy framework for the development of strategic marine emerging industries in the new era, guided by the scientific concept of development and enhanced by the capacity of independent innovation. Provide policy recommendations for actively promoting the development of strategic marine emerging industries. At the same time, it provides theoretical and methodological reference for the formulation and implementation of China's strategic marine emerging industry policies. On the basis of reviewing relevant theories of industrial policy, this article first defines China's strategic emerging industries and clarifies the connotation of China's strategic marine emerging industry development policies. Then, the paper conducts detailed analysis on the development policies of strategic marine emerging industries at home and abroad, and summarizes the experience of overseas strategic development policies for marine emerging industries. Finally, combining the above-mentioned comprehensive analysis, with the guidance of the scientific concept of development, the development strategy and concrete development policy of China's strategic emerging industries in the ocean are proposed.
\end{abstract}

Keywords: Ant colony algorithm; Complex maritime; Marine industry strategy

\section{INTRODUCTION}

To judge whether an industry is strategic or not, it usually depends on whether the industry can stand at the height of the national strategy and exert an important influence on economic development. Whether it can support the current economic operation and future economic growth, whether it can promote and guide the development of national economy and industrial structure, and whether it can represent the direction of future economic development and technological progress $[1,2,3]$. Strategic industries are not determined based on the local interests of the industry, nor are they only related to the development of the industry itself. They are related to the division of labor status of a country in the process of globalization and to the overall national strength and economic competitiveness of a country. To become a strategic industry must also have three basic characteristics: First, can quickly and effectively absorb innovation results, and access to new production functions associated with new technologies $[4,5,6]$. There is a huge market potential, is expected to obtain sustained high-speed growth. The third is that the correlation coefficient with other industries is relatively large, which can drive the development of related industries.

For a strategic emerging industry, it is necessary to possess key core technologies, have the characteristics of low resource energy consumption, large driving coefficient, multiple employment opportunities, and comprehensive benefits. Strategic marine emerging industries must be able to embody the country's marine strategic intentions, and 
play a positive role in the transformation of marine economic growth patterns and the adjustment of the marine industrial structure. Therefore, in the post-financial crisis era of the 21st century, China's strategic emerging industries in the ocean mainly refer to the ability to embody the nation's strategic intentions in the ocean $[7,8,9]$. With the ocean and high-tech as its chief feature, it has broad market prospects and huge potential for development in marine economic development. It can lead the development direction of the marine economy, and promote the development of the marine industry witch based on the definition of strategic marine emerging industries and the connotation of industrial development policies, strategic marine emerging industry development policies refer to the needs of marine economic development as the starting point. According to the characteristics of strategic marine emerging industries, the total number of plans, plans, measures, and laws and regulations formulated in terms of resource allocation and industrial regulation for the development of strategic marine emerging industries $[10,11,12]$.

Ant colonies can always find the shortest path from the nest to the food source, because the individual ants transfer information through a substance called Pheromone. Ants can stay on their way and perceive it in motion and use it to guide their direction of action. The ant colony's collective behavior manifests itself as a kind of positive feedback phenomenon of information: The more ants that go on a certain path, the greater the probability that the latter ant will choose this path until it finds the shortest path from the nest to the food source. This process is called the autocatalytic behavior of ants $[13,14,15]$.

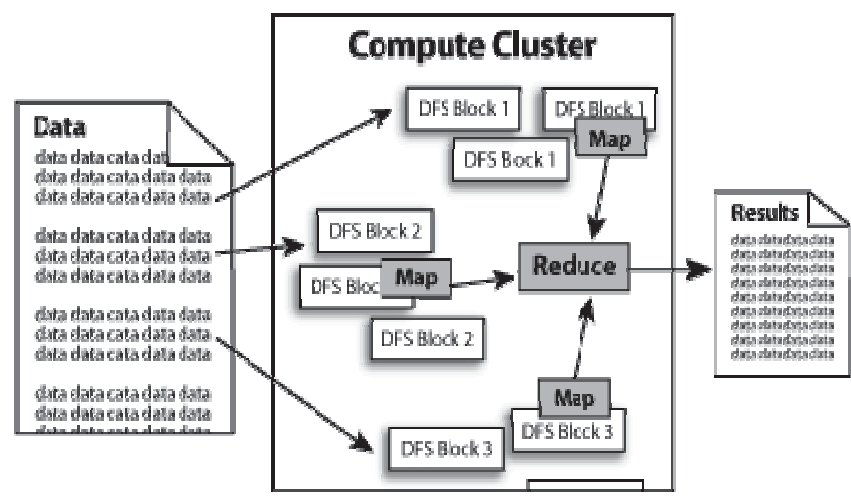

Fig. 1. Group project management resource dynamic scheduling model

\section{ANT COLONY ALGORITHM}

The scheduling of resources among group projects is one of the hot and difficult issues in project management in marine engineering and other fields. After analyzing the characteristics of this problem and subtly defining the heuristic information and scheduling model, the ant colony algorithm was introduced into the field. The example of ocean engineering project management shows that this method can reasonably resolve the dynamic scheduling of resources, which is a more effective and practical new method for resource management of group project management. The selection of the distribution phase in the dynamic allocation in the article is based on the opinions of experts. How to determine the time in each stage is still necessary for further study. Marine industry and territorial industry are not antagonistic to each other, but are interdependent. In the early days of ocean development, many marine industries were integrated into the terrestrial industry system, but with the deepening of marine development. The marine industry groups have become increasingly sophisticated. Vertical chain relations and horizontal cross-relationships have been established between various marine development activities. Their characteristics with respect to the terrestrial economy have initially appeared, and people have begun to separate them from the terrestrial economy. However, in the study of industrial structure relations, the close relationship between land and sea economy must be considered.

How to choose a leading industry in an area is an important part of the study of regional industrial structure and industrial policy. For a region, due to the limited resources and technology, it is impossible for various industrial sectors to adopt a balanced development strategy to maximize the most effective and effective use of limited resources and technologies. It can only focus on limited resources and technologies to give priority to the development of industries that have been carefully selected to play a leading and leading role in many industrial sectors. By giving priority to the development of leading industries to a certain extent, they will promote and promote the development of other industries, and seek to achieve coordinated development of the industrial structure in non-balanced development. Only in this way can the regional economy exert its greatest advantage and form an advantageous industry with its own characteristics. Therefore, the success of leading industry choices will directly determine whether a regional economy can develop rapidly and in a coordinated manner.

Aiming at the hot issues of marine engineering project management-the difficulties in the management of group projects, namely the rational and dynamic scheduling of resources such as manpower, funds, equipment and materials, a resource scheduling method based on ant colony algorithm (ACO) is proposed. This method utilizes the similarity between the resource scheduling problem and the traveling salesman problem (TSP) of group projects, combines the characteristics of the ACO algorithm, and compares the time that the resource needs to be used in each subproject with the urgent need of the resource as the information in the algorithm. The example of resource scheduling in marine project group project management shows that this method realizes the rational and dynamic scheduling of resources, and provides a more effective resource scheduling algorithm for marine project group project management, which can improve the project management of marine engineering and other fields in China. 


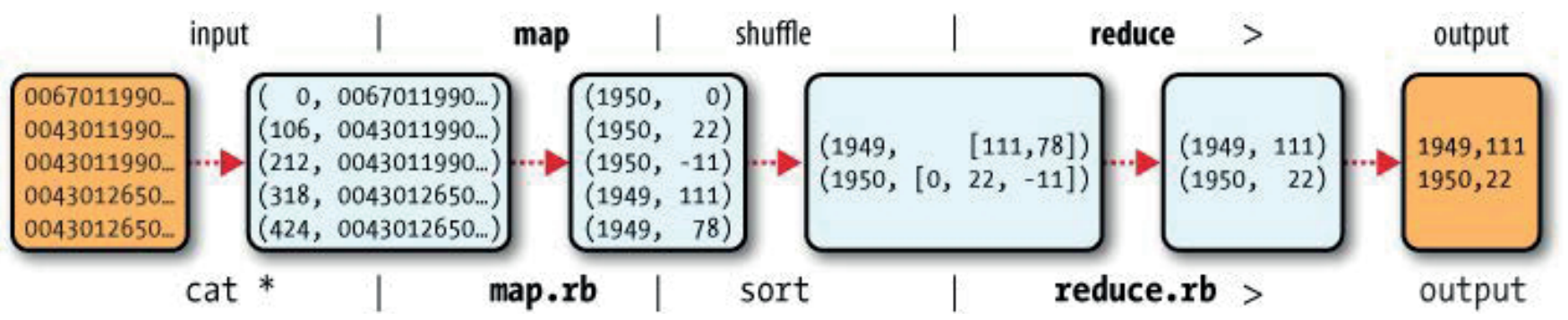

Fig. 2. The number of published papers on domestic marine industries in key journals

Child industry classification is the foundation for establishing the structure of the marine industry. It is the basis for analyzing the economic activities of various marine industry sectors and the relationship between them and their proportional relationship. It is also an important basis for the management of marine economy. Due to the diversity of research objectives, the diversity of marine industry classification is also formed. According to the history and trend of marine industry development and development, using technology, resources and time as three parallel standards, the marine industry can be divided into traditional marine industry, emerging marine industry and future marine industry. Industrial structure refers to the relationship between the production technology economic relations and the quantitative ratio between the various industries of the national economy in the process of social reproduction. The internationally accepted concept of industrial structure includes two aspects: First, the proportional relationship between industries in terms of production scale, the coordination and balanced development among industries.

\section{MARINE INDUSTRIAL STRUCTURE}

The theory of industrial structure optimization is based on the theory of industrial structure adjustment. Optimization of industrial structure refers to the process of industrial adjustment, the coordinated development of the industry, and meeting the growing needs of the society. Industrial structure optimization is a relative concept. It does not mean the absolute level of the industrial structure. It means that under the objective of the best national economic benefits, according to the characteristics of the country's geographical environment, resources, and economic development stage, through the adjustment of the industrial structure, it can achieve the state of coordinated development of various industries adapted to the above conditions. According to the selection of optimization criteria, the industrial structure optimization theory mainly includes the industrial structure rationalization theory and the industrial structure advanced theory. At present, the theoretical and industrial realms of the rationalization of industrial structure are inconsistent, and the research on the rationalization of industrial structure is mainly focused on the rationalization of benchmarks, the selection of strategic industries, and the maintenance of the coordinated development of the three industries, as well as mechanisms and motivation. As a constantly developing new field of human beings, the geography community has become increasingly interested in the relationship between marine economy and the development of marine resources and coastal planning. At present, the world's major maritime powers generally attach great importance to the development of the marine economy, and the marine industry has developed into a growth area that goes beyond the traditional industries. In the same way, the marine economy has rapidly become a new area for China's coastal provinces and cities to enhance their international competitiveness, participate in the economic cycle, and develop the national economy.

Coastline ocean economic density analysis is to obtain the relationship between marine industry development and marine space by analyzing and comparing the relationship between the total output value of marine economy and the coastline. From the comparison of the contribution of the marine industry output of the coastal line length of the coastal units of each province and city, it can be relatively intuitive to reflect the important position of Tianjin in the development of the marine economy in the country. The optimization of the marine industry structure refers to the rational allocation and coordinated development of the production factors of the marine industry. It is embodied in the full and effective use of marine natural resources, environment and human resources. In addition to the United States, other oceanic economic powers also actively take measures to promote the development of strategic marine emerging industries. The Japanese government has always attached great importance to the research and development of marine science and technology and proposed the integration of the ocean into the national strategy and global perspective. Focusing on the development of marine key technologies such as deep ocean submarine technology and deep-sea resource development technology, Japan has achieved remarkable achievements in the fields of marine biology, seawater desalination and comprehensive utilization.

This paper uses the basic principles of industrial economics, based on an analysis of the status quo of the development of China's strategic emerging industries in the ocean, and carefully scrutinizes the existing policies of China's strategic marine emerging industries. Based on the successful experience of foreign strategic development policies for marine emerging industries, China's strategic marine emerging industry development policy system has been constructed. First of all, China's strategic emerging 
industries in the ocean have related policies and regulations that are not perfect and lack corresponding management and coordination agencies. The shortage of high-level talent and the need for strengthening international cooperation. The emergence of these problems is attributed to the stage of industrial development and the constraints of technology, funds, and talents, which is precisely the starting point for solving these problems from the policy level.

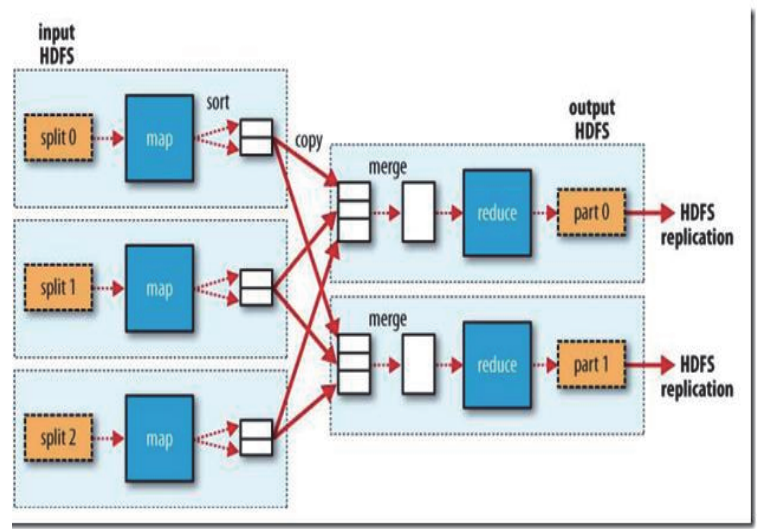

Fig. 3. Author collaboration network of marine industries

Combining the specific characteristics of China's strategic marine emerging industries and drawing on their common successes and models to formulate China's strategic marine emerging industry development policies, it is of positive significance for promoting the leap-forward development of China's strategic marine emerging industries. Thirdly, through the analysis of the characteristics, lacks, and policy needs of the existing development policies of China's strategic marine emerging industries, China's strategic marine emerging industry development policy system is constructed.

Tab. 1. Project team available resources

\begin{tabular}{|c|c|c|c|c|}
\hline \multirow{2}{*}{ Year } & \multicolumn{2}{|c|}{ Import and export } & \multicolumn{2}{c|}{ Import } \\
\cline { 2 - 5 } & Amount & Growth rate & Amount & Growth rate \\
\hline 1980 & 378.2 & 28.9 & 182.7 & 33.8 \\
\hline 1981 & 440.1 & 16.4 & 220.1 & 20.4 \\
\hline 1982 & 416.1 & -5.5 & 223.2 & 1.4 \\
\hline 1983 & 436.2 & 4.8 & 222.3 & -0.4 \\
\hline 1984 & 535.5 & 22.8 & 261.4 & 17.6 \\
\hline 1985 & 696.0 & 30.0 & 273.5 & 4.6 \\
\hline 1986 & 738.5 & 6.1 & 309.4 & 13.1 \\
\hline 1987 & 826.5 & 11.9 & 394.4 & 27.5 \\
\hline 1988 & 1027.8 & 24.4 & 475.2 & 20.5 \\
\hline 1989 & 1116.8 & 8.7 & 525.4 & 10.6 \\
\hline 1990 & 1154.4 & 3.4 & 620.9 & 18.2 \\
\hline 1991 & 1357.0 & 17.6 & 719.1 & 15.8 \\
\hline 1992 & 1655.3 & 22.0 & 849.4 & 18.1 \\
\hline 1993 & 1957.0 & 18.2 & 917.4 & 8.0 \\
\hline
\end{tabular}

\section{VALIDATION OF SIMULATION MODEL}

The strategic marine emerging industries have not developed to a complete marketization stage and require the guidance and regulation of the government. Therefore, how to establish a policy evaluation system from a macro perspective, establish a measure of the validity of policies, and grasp the effectiveness of policies must also be studied in depth. The development of strategic marine emerging industries that use ocean high technology as the main feature is to use advanced technology and equipment as the material basis. However, China's current marine technology equipment lags far behind the developed countries in the ocean. Development of offshore oil and gas resources and exploration of deep-sea mineral resources require a large number of imported technological equipment. Many advanced instruments and test equipment required by the Marine Science Research Institute also need to be imported from abroad. There are fewer technologies or equipment with independent intellectual property rights. This strong dependency has restricted the vigorous development of strategic marine emerging industries. In addition to relying on the strong support of ocean science and technology, the development of strategic marine emerging industries also needs sustained substantial funds to support its sustainable development. For a long time, the source of funds for the development of China's marine economy has mainly relied on government funding, with a single source channel and limited funds. For strategic marine emerging industries that require large amounts of funds to be injected, there is an urgent need to establish a diversified source of funds for the conflict between limited government funding and large capital requirements.

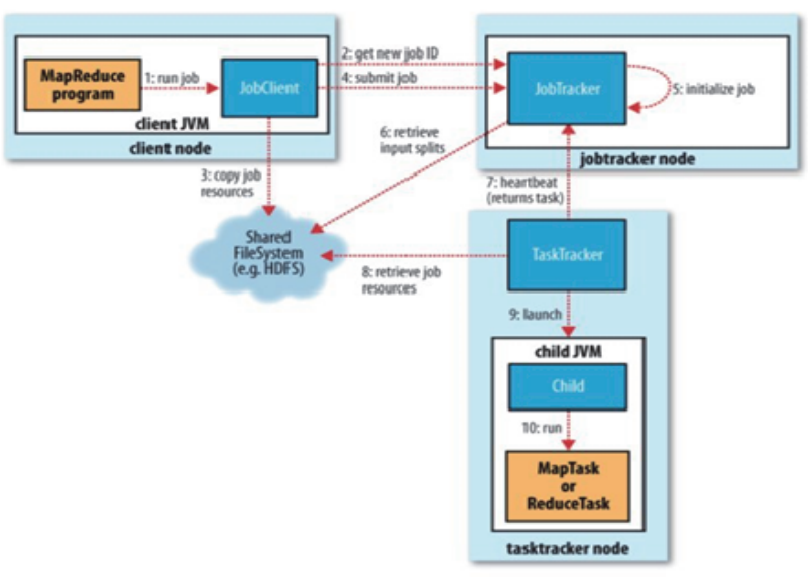

Fig. 4. The main research organizations network of marine industries

In recent years, venture capital and securities markets in Western countries have gradually replaced government investment and become an important source of technological development. China's strategic emerging industries in the ocean have also gradually adopted venture capital to finance the funds. However, the main source of China's venture capital is still the government's funding technology grants and bank's science and technology development loans. 
At a certain level of marine economic development, there will inevitably be a corresponding marine industrial structure. With the development of marine economy, the marine industrial structure will also undergo corresponding changes. The level of marine economic development is in line with the state of marine industrial structure:

$$
\begin{aligned}
&\left(\mathbf{F}_{N} \cdot \mathbf{Y}(:, m+1)\right)=\left(\mathbf{F}_{N} \cdot \mathbf{Y}(:, m)\right) \Theta \mathbf{P} \\
&+\left[\begin{array}{c}
1 \\
\vdots \\
1
\end{array}\right]_{N \times 1} \cdot\left(y_{k \cdot s+N_{c}-(m-1)}-y_{k \cdot s+s-(m-1)}\right) \\
& \mathbf{P}=\left[\alpha^{0}, \alpha^{1}, \ldots, \alpha^{N-1}\right]^{\mathrm{T}}, \alpha=e^{-j 2 \pi(1 / N)}
\end{aligned}
$$

The evolution of marine industrial structure can also measure the development process of marine economy. Different marine industrial structures have different economic benefits:

$$
z_{i}(k)=D_{i} \cdot \operatorname{row}_{i}\left(\mathbf{F}_{N}\right) \cdot(\mathbf{Y} \cdot \mathbf{w})=\operatorname{row}_{i}(\underbrace{\mathbf{F}_{N} \cdot \mathbf{Y}}_{T \mathrm{FFTs}}) \cdot \underbrace{\mathbf{w} \cdot D_{i}}_{\mathbf{w}_{i}}
$$

The marine economy includes all economic activities derived wholly or partly from the ocean or the Great Lakes basin:

$$
C_{N z}=C_{N x} \cdot \sum_{t} s_{i}^{N}(t)
$$

Scheduling problems are generally divided into dynamic scheduling problems. The scheduling problem of resource within the project group is to determine the dispatch and execution sequence of the resources according to the appropriate allocation strategy in a dynamic and realtime manner on the premise of satisfying certain resource constraints and priority constraint relationships:

$$
\left[\begin{array}{c}
z_{1}(k) \\
\vdots \\
z_{N}(k)
\end{array}\right]=\left[\begin{array}{ccc}
D_{1} & 0 & \cdots \\
0 & \ddots & 0 \\
0 & \cdots & D_{N}
\end{array}\right] \cdot \mathbf{F}_{N} \cdot(\mathbf{Y} \cdot \mathbf{w})
$$

In addition, the static pre-distribution is performed first, and then dynamic allocation is performed by real-time calculation of the resource usage and the degree of demand, so that the organic combination of dynamic scheduling and static scheduling can be realized:

$$
\mathbf{P}=\left[\frac{\mathbf{O} \mid \mathbf{I}_{N c}}{\mathbf{I}_{N}}\right]
$$

In the initial stage, China's marine industry was in its initial stage of development. The marine primary industry accounted for a large proportion, and the layout of the marine industry structure was prominent.

$$
\mathbf{Y}=\left[\begin{array}{cccc}
y_{k \cdot s+N_{c}+1} & y_{k \cdot s+N_{c}} & \cdots & y_{k \cdot s+N_{c}-T+2} \\
y_{k \cdot s+N_{c}+2} & y_{k \cdot s+N_{c}+1} & \cdots & y_{k \cdot s+N_{c}-T+3} \\
\vdots & \vdots & \ddots & \vdots \\
y_{(k+1) \cdot s} & y_{(k+1) \cdot s-1} & \cdots & y_{(k+1) \cdot s-T+1}
\end{array}\right]
$$

Therefore, the study of the marine industry during this period focused on the rational distribution of marine industrial structure and the development of marine resources:

$$
K_{x}(M, N)=\frac{C_{M x}}{\left[C_{N x}\right]^{M / N}}
$$

In the stage of steady growth, China's marine industry has developed rapidly and the marine industry has become an important growth point for regional economic growth:

$$
P_{r}(d)=\frac{P_{t} G_{t} G_{r} \lambda^{2}}{(4 \pi)^{2} d^{2} L}
$$

The optimization and upgrading of marine industrial structure is the core area of marine industry research. Under the background of the optimization and upgrading of China's industrial structure, the connotation of marine industrial structure has a strong quantitative color. Therefore, most studies have defined the marine industrial structure from the perspective of quantity, focusing on the quantitative relationship of the industrial structure, and lacking a qualitative perspective to explore the connotation of the marine industry structure.

\section{CONCLUSIONS}

The most common view is that the marine industrial structure refers to the proportional composition of the various marine industries and their interdependence and mutual restraint. In the crucial period of the restructuring and upgrading of the marine industry, we should further expand the connotation of the marine industry structure in terms of improving the quality of marine industry structure. The structural optimization of the marine industry focused on the current status of the marine industrial structure of the coastal provinces and key coastal cities in China, the selection and optimization of the leading industries, and the evolution of the marine industrial structure. According to the research scale, the study can be divided into two levels: the coastal provinces and cities and the coastal provinces and cities. In general, most of the existing studies on the optimization of the marine industry structure are based on the problems existing in the regional oceanic industry. Through empirical methods, the practical problems in the development of the regional ocean economy are analyzed and solved, which are characterized by timeliness and strong policies. However, as far as the theory itself is concerned, research on marine 
industrial structure mainly relies on the reference to other industrial development theories. It has not formed a set of industrial structure theory with the characteristics of marine economy and marine industry.

\section{ACKNOWLEDGEMENTS}

This work is supported by Nanhu Scholars Program for Young Scholars of XYNU with Grant No. 2017 B52.

\section{BIBLIOGRAPHY}

1. Semenov I.: The multidimensional approach to marine industry development: Part I. Obstacles and willingness to the EU marine industry reengineering, Polish Maritime Research, Vol.15, no.3, pp. 77-85, 2008.

2. Lazakis D.: Establishing an innovative and integrated reliability and criticality based maintenance strategy for the maritime industry, Cell, Vol.41, no.6, pp. 24-26, 2011.

3. Ludgate J J.: The Economic and Technical Impact of TBT Legislation on the USA Marine Industry, Applied and environmental microbiology, Vol.57, no.4, pp. 1194-1201, 1987.

4. Sanderson J.: Target identification in a complex maritime scene[C]// Motion Analysis and Tracking, Xplore, Vol.15, no.2, pp.1-4, 1999.

5. Zaidi F.: Maritime constellations: a complex network approach to shipping and ports, Maritime Policy \& Management, Vol.39, no.2, pp. 151-168, 2012.

6. Sanderson J G, Teal T J.: Target identification in complex maritime scenes, Vol.21, no.2, pp. 463 - 467, 1997.

7. Sanderson J G, Teal M K.: Characterisation of a complex maritime scene using Fourier space analysis to identify small craft[C]// Image Processing and ITS Applications, Seventh International Conference on,Vol.17, no.2, pp. 803-807, 1999.

8. Bukhari A C, Kim Y G.: A research on an intelligent multipurpose fuzzy semantic enhanced $3 D$ virtual reality simulator for complex maritime missions, Kluwer Academic Publishers, Vol.23, no.12, pp. 156-169, 2013.

9. Caschili S, Medda F R.: A Review of the Maritime Container Shipping Industry as a Complex Adaptive System, Interdisciplinary Description of Complex Systems, Vol.10, no.1, pp. 1-15, 2012.

10. Bukhari, Kim F A.: A research on an intelligent multipurpose fuzzy semantic enhanced $3 D$ virtual reality simulator for complex maritime missions, Applied Intelligence, Vol.38, no.2, pp. 193-209, 2013
11. Rub M G, Toksubayeva G P, Chernov B S.: Composition and origin of a tungsten-bearing magmatic complex in an area of Soviet Maritime Province, International Geology Review, Vol.12, no.3, pp. 313-326, 1970.

12. Engineer F G, Furman K C, Nemhauser G L.: A BranchPrice-and-Cut Algorithm for Single-Product Maritime Inventory Routing, Operations Research, Vol.60, no.1, pp. 106-122, 2012.

13. Rajendran C, Ziegler H.: Ant-colony algorithms for permutation flowshop scheduling to minimize makespan/ total flowtime of jobs, European Journal of Operational Research, Vol.155, no.2, pp. 426-438, 2004.

14. Shelokar P S, Jayaraman V K, Kulkarni B D.: An ant colony approach for clustering, Analytica Chimica Acta, Vol.509, no.2, pp. 187-195, 2004.

15. Liang Y C, Smith C E.: An ant colony optimization algorithm for the redundancy allocation problem, Transactions on Reliability, Vol.53, no.3, pp. 417-4233, 2004.

\section{CONTACT WITH THE AUTHOR}

Xiao Shen, Ph. D., e-mail:2012101050017@whu.edu.cn

School of Business, Xinyang Normal University, Xinyang, Henan, 464000 CHINA 